\title{
What Matters? Palliative Care, Ethics, and the COVID-19 Pandemic
}

\author{
Linda Sheahan (iD) Frank Brennan
}

Received: 29 April 2020 / Accepted: 10 September 2020

(C) Journal of Bioethical Inquiry Pty Ltd. 2020

\begin{abstract}
As is often the case in clinical ethics, the discourse in COVID-19 has focused primarily on difficult and controversial decision-making junctures such as how to decide who gets access to intensive care resources if demand outstrips supply. However, the lived experience of COVID-19 raises less controversial but arguably more profound moral questions around what it means to look after each other through the course of the pandemic and how this translates in care for the dying. This piece explores the interface between the pandemic, ethics, and the role of palliative care. We argue that the ethical discourse should be broader, and that the principles that underly the discipline of palliative care provide a solid ethical foundation for the care of all patients through the coronavirus pandemic.
\end{abstract}

Keywords Pandemic $\cdot$ Ethic(s) Palliative care $\cdot$ Virtue ethics · COVID 19

\footnotetext{
L. Sheahan

Sount East Sydney Local Health District and St George Hospital, Gray St, Kogarah, NSW 2217, Australia

L. Sheahan $(\bowtie)$

Sydney Health Ethics, University of Sydney, Sydney, Australia

e-mail: linda.sheahan@health.nsw.gov.au

F. Brennan

St George Hospital, Kogarah, NSW 2217, Australia

e-mail: frank.brennan@health.nsw.gov.au
}

If I had understood (when down the river you and I went swirling in that boat) that there were those who knew the ways of water and how to use the oars to keep afloat ... (Bruce Dawe, "White-Water Rafting and Palliative Care," 2007, 18-19)

The COVID-19 pandemic has swept the earth like a merciless storm. Abruptly and simultaneously, it has confronted the people, health professionals, and governments of the world with a cascade of issues. The objective of this article is to examine the interface of the pandemic, ethics, and the role of palliative care. Much attention has been placed on the ethics of resource allocation, especially ventilators, ICU beds, and personal protective equipment. We argue that the ethical discourse should be broader and that the principles that underly the discipline of palliative care provide a solid ethical foundation for the care of all patients through the pandemic, including those who are dying and their families.

Tragically, many people will become very ill and die from COVID-19 (Verity et al. 2020). In humanitarian crises, the traditional approach is to save as many people as possible. Numbers of lives saved or number of life years saved are common metrics through the necessary utilitarian lens (White and Lo 2020). The danger is that this becomes the new or even sole "locus of value," allowing other critically important things to be placed to one side or, potentially, ignored altogether. It becomes easier to lose sight of the deeply personal and individual nature of care. Related to this, it is easy to forget to "value" each person's particular journey-and respect 
for each person as themselves (and related notions of "human dignity") can be lost in the rapidly changing context of care delivery. We argue that this would represent tragedy on tragedy. If, on the other hand, there is a holistic response to the suffering of a patient who may die, what are the ethical foundations of that care?

\section{The Role of Palliative Care in a Pandemic Response}

In recent years there has been a growing emphasis on the integration of palliative care within humanitarian crises such as pandemics (Nouvet et al. 2018; Sphere Association 2018).

Historically, the discipline of palliative care arose in response to the needs of people with life-limiting illnesses. According to the World Health Organization, palliative care is an approach which improves the quality of life of patients and their families facing lifethreatening illness through the prevention and relief of suffering by means of early identification and assessment and treatment of pain and other problems - physical, psychosocial, and spiritual (World Health Organization 2014).

The structure of this response to the needs of a deteriorating and dying patient has a rigour that belies a sense, often expressed, that there is little to offer a person in that situation. If the latter attitude is adopted, nihilism prevails and patient, family, and clinicians may rapidly feel overwhelmed.

What are the ethics that underly and suffuse the discipline of palliative care and how do they apply in the context of the pandemic? We consider a virtue ethics approach in relation to healthcare workers, link this to an understanding of the obligation to relieve suffering in the COVID-19 context, and relate both to two core foundational principles of palliative care practice - the "principle of non-abandonment" and the "principle of personal care."

\section{A Virtue Ethics Approach}

Virtue ethics concentrates on the attributes and motivations of the virtuous person. As Zagzebski states: "The virtuous agent is motivated to seek (and subsequently produce) that which is right and good" (Zagzebski 1996, 119). As a way of ethical thinking, virtue ethics is different to utilitarianism (where the action is justified if the consequences are good) or deontological (is the action objectively right or wrong?). Virtue ethics concentrates on the moral character of the person. Examples of the virtues include the virtue or ethic of care, compassion, discernment, trustworthiness, integrity, and conscientiousness (Beauchamp and Childress 2001, 32). Using this lens, how should a clinician respond to a deteriorating and dying COVID-19 patient?

\section{The Virtue or Ethic of Care}

"Utilitarianism is most useful at the macro-level ... reminding us of problems of cost and allocation. Care reminds us never to lose sight of actual persons" (Manning 2012, 112).

Attempting to deconstruct the elements of caring is fraught as it involves so many tangible and intangible aspects. Arguably, it is endless in its variety. Nevertheless, ethicists have isolated four central processes in an ethic of care: moral attention, sympathetic understanding, relationship awareness, and harmony and accommodation (Manning 2012). In the clinical setting of a seriously ill or dying patient with COVID-19, this would involve a health professional being morally attentive to the needs of the patient and family, sympathetically understanding of their experience, and sensitive to a set of relationships: doctor-patient, and the relationship between the patient and other members of a multi-disciplinary team.

\section{Compassion}

Compassion is critical for all seriously ill patients in the pandemic. As Beauchamp and Childress state: "The virtue of compassion combines an attitude of active regard for another's welfare with an imaginative awareness and emotional response of sympathy, tenderness, and discomfort at another's misfortune or suffering" (Beauchamp and Childress 2001, 32). Recognizing then responding to suffering is key (Cassell 1982). The practical fulfilment of that ethic in any humanitarian crisis is the challenge that confronts all clinicians.

\section{Discernment}

Discernment is the ability to make good judgements. Aristotle expressed this as practical wisdom (Reeve 2013). One important aspect of this is to be well-informed. In the context of the pandemic, this requiresindeed necessitates - health professionals having a good 
understanding of the pathophysiology of COVID-19, its likely trajectory, the anticipated symptoms and their management, and the manner and appropriate care of the dying, anticipating the related constraints. There is, therefore, an obligation on palliative care health professionals to prepare, educate, and guide their colleagues outside the discipline in the principles of the discipline. This wisdom may well need to reach into the granularthe most appropriate classes and doses of medications for symptoms such as shortness of breath, cough, secretions, and feelings of suffocation and distress. Equally, that wisdom includes the manner of, and approach to, the support of the family, and indeed extends beyond the dying person and their family to include those clinicians providing care in this heightened and anxiety provoking milieu.

\section{Trustworthiness, Integrity, and Conscientiousness}

Each of these virtues are important in all health professionals in all circumstances, including in the care of COVID-19 patients. Patients trust that their health professionals will act in their best interest. In the care of deteriorating and dying patients, an example is the trust patients place in their health professionals to recognize their limits in symptom management and care of the dying and to be willing to refer to clinicians with those skills, including, but not confined to, the discipline of palliative care. That recognition is also an aspect of discernment. An example of integrity and conscientiousness would be a team of palliative care health professionals making themselves available to, and readily contactable for, their colleagues.

The Principle of Non-Abandonment and the Principle of Personal Care

Consistent with the ethic of care is a founding principle of palliative care practice: the principle of non-abandonment. Broadly, this means that no matter how poor the patient's condition is, something can be done, and the skills of palliative care can and should be applied. This principle has profound implications in the present pandemic. Where supportive intensive treatment such as ventilatory support is not offered or exhausted and rationing or triaging processes have been triggered based on resource scarcity, doctors may surrender to nihilism. They may feel there is nothing more that can be done. There may be inadequate response to symptom management or psychospiritual distress. Patients may be dying alone. Patients may feel they are drowning in fluids, be agitated, or be profoundly anguished. This foundational principle reminds us as of our professional obligation not to surrender to nihilism.

The second relevant foundational principle is the principle of personal care: in palliative care practice we consider each patient in their full particularity (Hanks et al. 2010). This looks to autonomy and respect for persons and how these concepts relate to complex ideas such as the inner worth or value of the human person (Sulmasy 2008; Kant [1797] 1991; Field and Cassel 1997; Ashby 1997). This is an important foundation to the ethic of care and it reminds us that the person themselves is the core locus of "value" in managing their dying. As Dame Cicely Saunders put it: "you matter because you are you, and you matter to the end of your life" (quoted in Twycross 2006).

It is important to note two facts. Firstly, that palliative care is not the only discipline that has this focus. Indeed, it is an objective of all medical care. Second, palliative care cannot guarantee perfection and strives daily to meet the high standards of its definition. However, both of these principles inform how we consider both the challenges and the obligation to provide palliative care for the dying in the context of COVID-19.

How do we understand suffering in the context of the symptomatic, deteriorating, and dying patient with COVID-19? The very nature of this highly contagious disease means that the usual response to a deteriorating and dying patient and their family is upended: patients being unable to have visitations or farewells from family or loved ones; pastoral care workers embargoed; limited access to medical and nursing personnel (concerned about their own personal protection and potentially overwhelmed); the challenges of any health professional sitting for long periods with the patient to speak, counsel, and reassure; issues of access to medications, including opioids and sedatives; the loss of touch and togetherness as a result of isolation requirements; and that reality that patients may be dying alone. Virtually every aspect of the daily work in caring for the dying is either circumscribed or absent. That suffering flows into complicated grief and bereavement: limited visitation rights; sudden, sometimes catastrophic, deterioration with limited opportunity to prepare and farewell their loved one; small funerals that may be rushed and stripped of ritual; and multiple deaths in the one family or circle of people. These sources of suffering challenge 
the foundations of ethical practice as described, highlight the risk of us not attending to and contributing to "tragedy on tragedy," and remind us of the importance of solidarity and compassion.

\section{Conclusion}

The pandemic will mean that all relevant disciplines, simultaneously challenged, will learn from each other. What could other disciplines learn from palliative care?

The first lesson may be a broadening of the sense of medicine and nursing as professions. Simply because ventilatory support is unavailable, deemed inappropriate, or failing to clinically improve the condition of a patient, does not mean that nothing more can be done for that person. What may be revelatory to other disciplines is the breadth and depth of the discipline of palliative care: that the content of beneficence and "care" is broad not narrow, that the principle of non-abandonment prevails, that the dignity of person is critical throughout, and that the response to the suffering of patients can be met by a sophistication of technical and personal skills in potentially novel and creative ways given the unprecedented constraints. We should never lose sight of the deeply human nature of caring for other through this pandemic.

Consciously or otherwise, clinicians set an ethical tone. That tone at the time of the illness, deterioration, and dying of a patient can be remembered forever by families. These issues - singly and collectively - cause significant moral distress in health practitioners (Ducharlet et al. 2020). To practice the highest standards of palliative care may seem impossible in this context, but it requires ingenuity and high degrees of flexibility in each patient encounter. Practicing the art of the possible may be all that is possible. But practicing, nevertheless, and never abandoning.

\section{References}

Ashby, M. 1997. The fallacies of death causation in palliative care. The Medical Journal of Australia 166(4): 176-177.

Beauchamp, T.L., and J.F Childress. 2001. Principles of biomedical ethics. Oxford: Oxford University Press.
Cassell, E. 1982. The nature of suffering and the goals of medicine. The New England Journal of Medicine 306(11): 639645.

Dawe, B. 2007. White-water rafting and palliative care. In The best Australian poems of 2007, edited by P. Rose. Melbourne: Black Inc Press.

Ducharlet, K., D. Martin, F. Brennan, et al. 2020. Forthcoming. Moral distress in medicine during a pandemic. Submitted for peer review 23 April.

Field, M., and C.K. Cassel. 1997. Approaching death: Improving care at the end of life. Washington, DC: National Academy Press.

Hanks, G., N.I. Cherny, N.A. Christakis, M. Fallon, S. Kaasa, and R.K. Portenoy. 2010. Oxford textbook of palliative medicine, 4th ed. Oxford: Oxford University Press.

Kant I. (1797) 1991. The metaphysics of morals, part II: The metaphysical principles of virtue. Translated by M. Gregor. New York: Cambridge University Press.

Manning, R.C. 2012. A care approach. In A companion to bioethics, 2nd ed., edited by H. Kuhse and P. Singer. Oxford: Wiley-Blackwell.

Nouvet, E., M. Sivaram, K. Bezanson, et al. 2018. Palliative care in humanitarian crises: A review of the literature. Journal of International Humanitarian Action 3(5). https://doi. org/10.1186/s41018-018-0033-8.

Reeve, C.D.C., trans. 2013. Aristotle on practical wisdom: Nicomachean ethics VI. Cambridge: Harvard University Press.

Sphere Association. 2018. Humanitarian charter and minimum standards in humanitarian response. Rugby: Practical Action Publishing.

Sulmasy, D.P. 2008. Dignity and bioethics: History, theory and selected applications. In Human dignity and bioethics: Essays commissioned by the President's Council on Bioethics. https://bioethicsarchive.georgetown. edu/pcbe/reports/human_dignity/chapter18.html Printed 2009 in Human Dignity and Bioethics, edited by B.T. Lanigan. New York: Nova Science Publishers.

Twycross, R. 2006. Recollection: "You matter because you are you." Church Times, November 2. https://www.churchtimes. co.uk/articles/2006/17-march/gazette/recollection-youmatter-because-you-are-you. Accessed April 29, 2020.

Verity R., L.C. Okell, I. Dorigatti, et al. 2020. Estimates of the severity of coronavirus disease 2019: A model-based analysis. The Lancet Infectious Diseases 20(6): 669-677.

White, D.B, and B. Lo. 2020. A framework for rationing ventilators and critical care beds during the COVID-19 pandemic. JAMA 323(18): 1773-1774.

World Health Organization. 2014. WHO definition of palliative care. http://www.who.int/cancer/palliative/definition/en/. Accessed March 21, 2020.

Zagzebski, L.T. 1996. Virtues of the mind: An inquiry into the nature of virtue and the ethical foundations of knowledge. New York: Cambridge University Press.

Publisher's note Springer Nature remains neutral with regard to jurisdictional claims in published maps and institutional affiliations. 